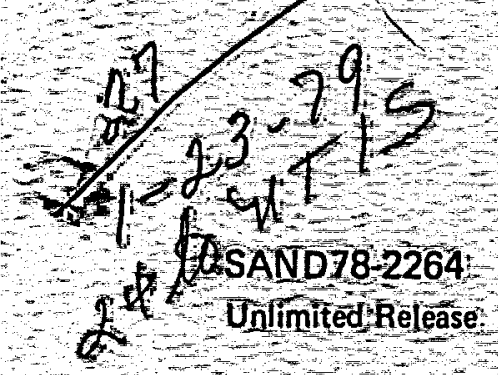

\title{
Quartz Resonator Pressure Gauge: Design and Fabrication Technology
}

Errol P EerNisse

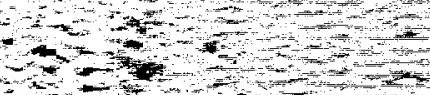

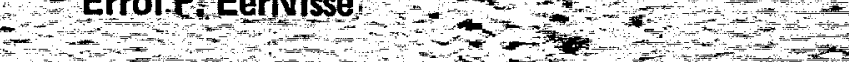

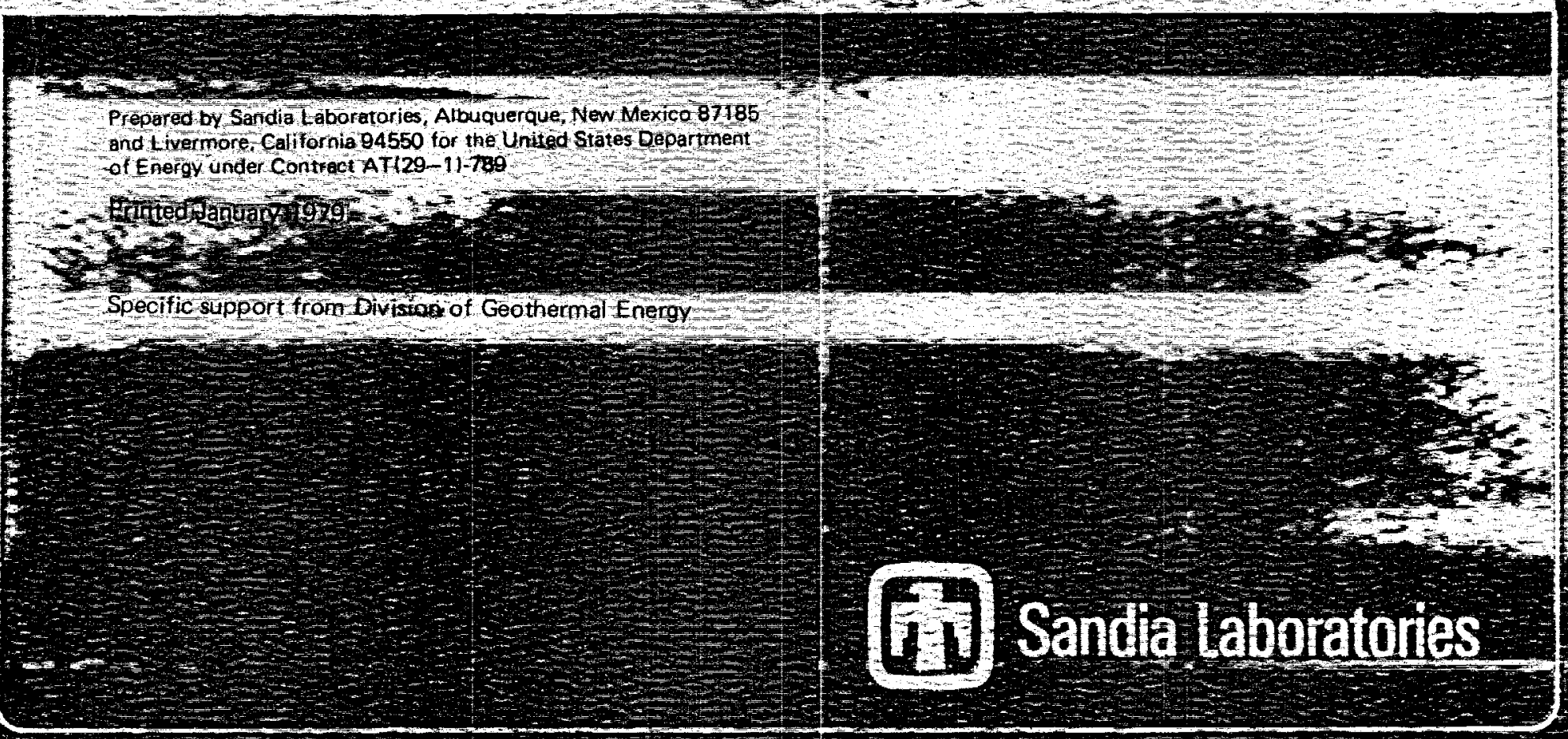




\section{DISCLAIMER}

This report was prepared as an account of work sponsored by an agency of the United States Government. Neither the United States Government nor any agency Thereof, nor any of their employees, makes any warranty, express or implied, or assumes any legal liability or responsibility for the accuracy, completeness, or usefulness of any information, apparatus, product, or process disclosed, or represents that its use would not infringe privately owned rights. Reference herein to any specific commercial product, process, or service by trade name, trademark, manufacturer, or otherwise does not necessarily constitute or imply its endorsement, recommendation, or favoring by the United States Government or any agency thereof. The views and opinions of authors expressed herein do not necessarily state or reflect those of the United States Government or any agency thereof. 


\section{DISCLAIMER}

Portions of this document may be illegible in electronic image products. Images are produced from the best available original document. 
Issued by Sandia Laboratories, operated for the United States Department of Energy by Sandia Corporation.

\section{NOTICE}

This report was prepared as an account of work sponsored by the United States Government. Neither the United States nor the Department of Energy, nor any of their employees, nor any of their contractors, subcontractors, or their employees. makes any warranty, express or implied, or assumes any legal liability or responsibility for the accuracy, completeness or usefulness of any information, apparatus, product or process disclosed, or represents that its use would not infringe privately owned rights.

Printed in the United States of America

Available from

National Technical Information Service

U.S. Department of Commerce

5285 Port Royal Road

Springfield, $\mathrm{VA}=22161$

Price : Printed Copy $\$ 4.50$; Nicrofiche $\$ 3.00$ 


\author{
SAND78-2264 \\ Unlimited Release \\ Printed December 1978
}

\begin{abstract}
QUARTZ RESONATOR PRESSURE GAUGE: DESIGN
AND FABRICATION TECHNOLOGY
\end{abstract}

Errol P. EerNisse

Solid State Device Physics Division 5133

Sandia Laboratories

Albuquerque, New Mexico 87185

\begin{abstract}
This document provides a repository for the base technology used in designing and fabricating the Sandia Quartz Resonator Pressure Gauges for geothermal well logging. The following topics are treated: resonator design (crystallographic orientation), transducer design (static stress analysis and transfer function), electrode technology, and assembly details. In addition, preliminary results of pressure measurements at

$275^{\circ}$ C are presented.

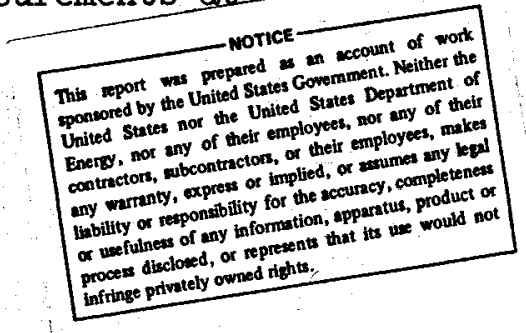


.

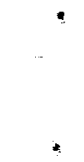

$\tilde{j}$

s.

$\div$ 
TABLE OF CONTENTS

Page

Introduction

Resonator Design . $\quad 9$

Origin of Transducer Effect 9

Frequency vs Temperature Effects 9

Mechanical $Q$ vs Temperature Effects $\quad 10$

Temperature Dependence of Pressure Sensitivity $\quad$ II

Transducer Design Considerations 13

$\begin{array}{ll}\text { Transducer Concept } & 13\end{array}$

Response of Resonator Plate to Initial Stresses 13

Transfer Function: Theory 14

Transfer Function: Theoretical Results and Experimental Confirmation $\quad 17$

$\begin{array}{ll}\text { Maximum Pressure Considerations } & 19\end{array}$

Fabrication Technology $\quad 22$

Electrode Considerations

Bonding Agent 23

Preliminary Pressure Measurements at $275^{\circ} \mathrm{C} \quad 25$

Conclusions 26

Acknowledgements $\quad 26$

References $\quad 27$ 
?

$\therefore$ 


\section{INTRODUCTION}

Development of well logging instrumentation for survey of geothermal energy resources is hampered because the down-hole high temperatures $\left(300^{\circ} \mathrm{C}\right.$ or higher) far exceed the operating regimes of ordinary electronics and transducers. The same problems arise in deeper oil and gas wells. One of the most useful logging tools being applied in the oil and gas industry is high-resolution pressure measurement. Fluid density measurements, reservoir determination by blow-off, and adjacent well interactions are most easily made if down-hole pressure can be measured with high resolution. Presently, the highest pressure resolution measurements are made with commercially available quartz resonator transducers. ${ }^{1,2}$ However, the present technology of these devices is temperature limited on the high side by approximately $125^{\circ}$ C. It is the intent of our present work to develop a high temperature $\left(300^{\circ} \mathrm{C}\right)$, high resolution pressure gauge based on quartz resonator concepts. Specific goals are 7500 psi full scale indication, $300^{\circ} \mathrm{C}$ upper temperature limit, and a resolution of $1 \mathrm{ppm}$, i.e., minimum detectable fluctuation on top of a full scale pressure background of 0.01 psi.. It is

desirable to also have the hysteresis in the measurements, $1 . e .$, the change in reading when approaching a given pressure from above and below, less than $1 \mathrm{ppm}$. The hysteresis is difficult to evaluate and is taken here to be the offset at zero gauge pressure after an excursion to full scale.

The approach taken to date is similar to the Hewlett-Packard design ${ }^{1}$, a thickness-shear mode plate resonator with a uniform force proportional to pressure acting around the perimeter of the resonator plate. Numerous technological changes are necessary, however, to move the temperature range up to $300^{\circ}$ C. In addition, the intent is to satisfy the technical require- 
ments at a cost per transducer lower than the presently available devices. The present article is a resource document containing detailed descriptions of the base design and technology considerations leading to a high temperature quartz resonator pressure transducer. Preliminary results of pressure measurements at $275^{\circ} \mathrm{C}$ are presented as a demonstration of viability. 


\section{RESONATOR IDESIGN}

\section{Origin of Transducer Effect}

The quartz resonator pressure transducer operates on the principle that mechanical resonance frequencies, which are linear elastic phenomena, are shifted by nonlinear elastic effects. Quartz resonators have extremely stable mechanical resonances due to the high purity of quartz, to the accumulation of experience in cleanliness of fabrication and packaging, and to careful resonator design for obtaining well defined, high $Q$ mechanical resonant modes. Frequency stabilities in environments where temperature is constant and there are no mechanical biases (initial stresses) acting on the resonator plate have been observed up to $2 \times 10^{-12}$ over a 10 sec period. Stabilities of $1 \times 10^{-9}$ over time periods of hours are now routine. The high resolution of quartz resonator transducers comes from this inherent frequency stability and the fact that initial stresses in the resonator plate of magnitudes the order of the elastic limit of quartz can reversibly shift the resonant frequencies as much as $1 \times 10^{-3}$ through nonlinear elastic effects. 3,4 Frequency vs Temperature Effects

Unfortunately, small changes in temperature can shift the resonant frequencies by amounts comparable to the stress-related frequency changes. It is necessary to choose the resonator design (crystallographic orientation of the resonator structure) such that temperature effects are small compared to stress effects. This means operation at a turnover point in the frequencytemperature ( $f$ vs $T$ ) characteristlc of the resonator so that the linear, or first-order, temperature effects are eliminated. The thickness-shear vibrational modes of plate resonators are the most useful plate modes because they exhibit turnovers in their $f$ vs $T$ characteristics. All of the high 
frequency stability accomplishments in the past have come from plate resonators operating in the thickness-shear mode of vibration. The commercially available plate resonator transducer of interest here ${ }^{1}$ utilizes the common BTcut resonator with a parabolic $f$ vs $T$. For high temperature operation at $275^{\circ} \mathrm{C}$, the curvature of $\mathrm{f}$ vs $\mathrm{T}$ (second order effect) is large and equal to $0.19 \mathrm{ppm} /{ }^{\circ} \mathrm{C}^{2}$. Thus a temperature change of $1^{\circ} \mathrm{C}$ causes a frequency shift $\Delta f / f$ of $0.19 \mathrm{ppm}$. Since $0.01 \mathrm{psi}$ causes a $\Delta \mathrm{f} / \mathrm{f}$ the order of $1 \times 10^{-9}$ in most transducer designs, this high curvature places stringent requirements on the temperature environments.

One of the first steps taken in development of a high temperature technology was a search for crystallographic orientations where temperature effects on $f$ were minimum around $300^{\circ} \mathrm{C}$. The rotated $\mathrm{X}$-cut was identified as the most useful orientation. The details of this orientation have been recently published. ${ }^{5}$ It is identified as the $(x y l) \theta$ orientation in standard notation $^{6}$ (see Fig. 1). A typical $f$ vs $T$ plot is shown in Fig. 2. The $f$ vs T characteristic of the common AT-cut is included in Fig. 2 for comparison. As seen in Fig. 2, the overall frequency shifts are markedly less for the rotated $\mathrm{X}$-cut and the curvature at the $275^{\circ} \mathrm{C}$ turnover point is less as compared to the AT-cut. The rotated X-cut has a curvature at $275^{\circ} \mathrm{C}$ of $0.04 \mathrm{ppm} /{ }^{\circ} \mathrm{C}^{2}$ as compared to 0.12 for the AT-cut and 0.19 for the BT-cut. It is clear that the rotated $\mathrm{X}$-cut has distinct advantages for ovencontrolled applications at turnover and even more so for applications where temperature cannot be controlled.

Figure 3 contains the necessary information for choosing the orientation angle $\theta$ to obtain the desired $f$ vs $T$ behavior for the rotated $X$-cut. Mechanical Q $\underline{\text { vs Temperature Effects }}$

Another consideration for high temperature applications of quartz 
resonators is the mechanical Q. Natural quartz has been observed to suf'er. a drop in mechanical $Q$ for temperatures above $200^{\circ} \mathrm{C}$, presumably due to acoustic absorption centers related to impurities. Our $Q$ data on the rotated $\mathrm{X}$-cuts made from natural quartz have been erratic. One lot of resonators suffered a severe $Q$ drop to values as low as 30,000 above $250^{\circ} \mathrm{C}$, a second lot showed a less severe effect and maintained $Q^{\prime}$ 's of over 100,000 above $250^{\circ} \mathrm{C}$.

A low $Q$ is undesirable for several reasons. The series resistance of the resonator goes roughly as $Q^{-1}$ and oscillator circuits normally cannot accommodate large changes in series resistance. Low $Q$ resonant circuits have fm noise which prohibits stable frequency operation. We find that a $Q$ of 100,000 allows frequencies stable to at least $1 \times 10^{-9}$.

The present investigation is inconclusive about the $Q$ degradation at high temperatures. Presently we are investigating electrically swept material which is of much higher purity and which should not show a $Q$ drop at high temperatures. At the very least, electrically swept material should be more controllable so that one can design around any $Q$ drop. Temperature Dependence of Pressure Sensitivity

If the frequency shifts due to initial stresses are large, it is possible to have the $f$ vs $T$ characteristic shift along the $T$ axis. Alternately stated, there may be a temperature dependence of the stress-caused frequency shifts. The effect is due to the next higher order of nonlinearity in the quartz which couples stress effects to temperature effects. If the effect is present, the turnover point moves away from the zero initial stress value and the frequency changes due to temperature fluctuations can become comparable to the stress-caused frequency shifts under measurement. This effect is not well documented in the literature ${ }^{I, 7}$ and it is impossible 
to calculate presently because the necessary parameters such as the temperature dependences of the third order elastic stiffness coefficients are not known.

Experimentally it is found that the BT-cut has a small effect. Other crystallographic cuts are less well characterized. The effect is unknown at this stage of development for the rotated X-cut. Data on the effect will evolve naturally as our program advances.

One approach used in quartz resonator accelerometer designs to eliminate the effect is to use a one-dimensional initial stress pattern. The lower symmetry of this initial stress pattern allows one more degree of freedom in choice of crystallographic orientation for the resonator plate, namely the direction of application of the one-dimensional initial stress in the plane of the resonator plate. ${ }^{8}$ This additional degree of freedom allows adjustment of the temperature dependence of the stress effects to the desired value of zero. Such an approach can be taken in our pressure transducer work if it is found that the temperature-stress coupling effect is significant for the rotated $\mathrm{X}$-cut. 


\section{TRANSDUCER DESIGN CONSIDERATIONS}

Transducer Concept

The proposed pressure gauge, or transducer, concept is shown in Fig. 4. A circular resonator plate is enclosed by two hollowed-out quartz end caps of the same crystallographic orientation as the resonator plate. The net force on the resonator when the transducer is subjected to hydrostatic pressure is a radially directed force uniformly distributed around the perimeter. This gauge concept is similar to that offered commercially for lower temperature applications. ${ }^{1}$

Response of Resonator Plate to Initial Stresses

The response of the resonator plate to radially directed forces can be calculated at room temperature with the published values for the thirdorder elastic coefficients. This has been done for numerous crystallographic cuts including the rotated $\mathrm{X}$-cut and published in the frequency control literature. ${ }^{3}$ The frequency shift is given by

$$
\frac{\Delta f}{f}=K \bar{T}
$$

where $\bar{T}$ is the uniform initial stress caused by the symmetric force pattern and $K$ is dependent on crystallographic orientation. Figure 5 shows $K$ for the technologically important family of thickness-shear mode cuts (yxwl) $\phi, \theta 6$ which have a turnover point in their $f$ vs $T$ characteristics. The rotated $X$-cut is in this family and is given by (yxwl) $30^{\circ}, \theta$. As seen in Fig. 5 , it has a $\mathrm{K}$ vilue of $+1.54 \times 10^{-12}$, which is magnitude-wise one of the largest to be obtained in quartz (compare this value to the others in Fig. 5). The BT-cut, which is on the other technologically important branch of the 
(yxwl) $\phi, \theta$ family with $\theta \approx-49^{\circ}$, is the only other thickness shear mode cut of interest. It has a $\mathrm{K}$ value of $2.7 \times 10^{-12}$.

It is clear that almost any orientation of thickness shear mode resonator will be sensitive to the symmetric initial stress pattern set up by the transducer design in Fig. 4. The exception is any orientation near the SC-cut shown in Fig. 5 where the stress-caused frequency shifts go to zero. Orientation is not of primary concern, therefore, as far as sensitivity is concerned.

\section{Transfer Function: Theory}

of importance is the relation between the initial stress in the resonator plate and the hydrostatic pressure. There is an opportunity for mechanical advantage because the resonator must help support the cylindrical shells on each side of the resonator plate (see Fig. 4). This mechanical advantage relation is called the transfer function $F$. It is defined as

$$
F=\bar{T} / P
$$

where $P$ is the hydrostatic pressure.

A cross-section of the transducer design is given in Fig. 6 along with definition of dimensional variables. Earlier work ${ }^{1}$ has characterized the transfer function for the case where the unsupported cylinder length $\ell$ is much greater than the shell thickness $h$. Their result is given by

$$
F=1+\left[\beta \tau_{R} C+h(I-v) a\right]^{-1}
$$

where $\tau_{R}$ is resonator thickness, a is radius, $v$ is Poission's ratio, $\beta$ is given by 


$$
B=\left[3\left(1-v^{2}\right) / a^{2} h^{2}\right]^{1 / 4}
$$

and $C$ is given by

$$
C=\frac{(\sinh \beta l+\sin \beta l)}{2(\cosh \beta l-\cos \beta l)}
$$

Equation 3 was derived for Isotropic material and for long $\&$ where effects at the end caps and joints are isolated from the resonator plate by the cylindrical shel1. The agreement between experiment and theory (Eq. 3) is good ${ }^{1}$ for long $l$.

The use of a long $l$ in the design represents the major contributing factor to the present high cost of fabrication because in order to place the joints and end caps far away from the resonator plate, the plate must be formed by coring into a sizable piece of quartz while maintaining crystallographic orientation to an arc minute or better. In the interest of lowering the cost of the transducer, shorter $\&$ values have been investigated theoretically and experimentally. shortening of $\ell$ brings in effects of the end cap flexing under pressure, but these are repeatable and analyzable. The sacrifice in shortening $l$ is in the movement of the joints nearer to the resonator plate. Placement of the joints near the resonator will introduce some hysteresis from stress relaxation in the joining compound. This sacrifice has not been evaluated completely yet for its implication in well logging application but will be studied In our continuing program.

The end cap effects are called here thrust effects for obvious reasons. As the pressure increases, the end caps bow inward. At the point of attach- 
ment between the cylinder and the end cap, there is an outward thrust $\mathrm{Q}_{\mathrm{K}}$ and moment $M_{E}$ due to the bowing of the end cap. This thrust is opposite to the desired inward forces arising from the pressure acting on the cylinder outer surface and reduces the transfer function $F$ if $l$ is not much greater than $h$.

The forces acting on the cylinder because of this thrust effect are shown in Fig. 6. Tables I and II list the appropriate expressions which must be included to form the complete theory for the static analysis under the assumption of isotropic elastic properties. The expressions in Tables I and II arise from application of thin shell theory ${ }^{9}$ for the cylindrical shell, bending plate theory ${ }^{10}$ for the end caps, and matching of the mechanical displacements and slopes at the boundaries. The reader is spared the tedious algebra leading to Tables I and II. The expressions in Tables I and II are solved for $Q_{R}$, the radial force distribution (in dyn $/ \mathrm{cm}$ ) acting around the periphery of the resonator plate, in terms of $P$. The transfer function.is then given by

$$
F=F_{0}-2 Q_{R} / \tau_{R}
$$

where $F_{0}$ is found from Eq. 3.

The thin shell theory holds with reasonable accuracy only for $\ell$ greater than approximately $4 \mathrm{~h}$. For $\ell<\mathrm{h}$, one can use a plate theory. The short $\ell$ case is of interest because of its simplicity in fabrication. It is shown in Fig. 7, where the cylinder is now a plate with a hole in the center. The case neglecting end thrust and the end thrust contribution are both indicated in Fig. 7. The relations for the radial mechanical displacements in the case of the forces in Fig. 7 can be found again in textbooks. 10 
We assume here that the slope of the cylinder remains zero because of moments acting in the interface regions (short cylinder rigid). Matching of the displacements at the resonator/cylinder interface for the two cases in Fig. 7 gives relations between $Q_{R}$ and $Q_{E}$ and between $Q_{R}^{\prime}$ and $Q_{E}^{-}$. Matching of the displacements at the cylinder/end cap interface gives a relation between $Q_{R}, Q_{E}$, and $P$ and between $Q_{R}^{\prime}, Q_{E}^{\prime}$, and $P$. The results are stated in Table III. Once $Q_{R}$ and $Q_{R}^{-}$are found from Table III, $F$ can be found from

$$
F=1+2 Q_{R} / \tau_{R}+2 Q_{R}^{-} / \tau_{R}
$$

This plate theory approach should be usefur for $\ell \leq h$.

For $h \leq \ell \leq 4 h$ the static analysis is not straightforward and requires numerical techniques. Extrapolation between the long $\&$ theory in Tables I and II and the short $\&$ theory in Table III will give a qualitative feeling for the transfer function.

Transfer Function: Theoretical Results and Experimental Confirmation

The equations in Tables I-III and Eq. 3 have been used to characterize the transfer function of the pressure transducer in Fig. 4 as a function of dimensions. We consider first the effect of resonator thickness on the overall transfer function. Figure 8 compares calculated results of Table III and Eq. 3, both short $\ell$ (plate theory) and long $\ell$ (shell theory), for a $6 \mathrm{MHz}$ resonator in fundamental mode $\left(\tau_{R}=0.03 \mathrm{~cm}\right)$ and fifth overtone $\left(\tau_{R}=0.15 \mathrm{~cm}\right)$ configurations. End thrust effects are not included. It is clear that thin resonator plates offer the highest mechanical advantage, i.e., the largest transfer function. In fact, the largest possible transfer function arises in a configuration where the resonator is so thin that it offers no resistance to the cylinder closing under pressure. This limit is 
Given by matching the displacement in a radially compressed disc

$$
\left.\mathrm{U}\right|_{\mathrm{r}=\mathrm{a}}=\frac{\overline{\mathrm{T}}(1-v) \mathrm{a}}{\mathrm{E}}
$$

where $\mathrm{E}$ is Young's modulus, to the radial displacement by a long tube

$$
w=-\frac{P a^{2}}{\operatorname{Eh}}
$$

Equating Eqs. 8 and 9,

$$
\overline{\mathrm{T}}=-\frac{\mathrm{aP}}{\mathrm{h}(1-v)} \text {, }
$$

which will hold if the cylinder wall is flexually rigid compared to the radial compressibility of the resonator disc. This limit is almost attained in Fig. 8 for the thinner fundamental mode plate at large $\ell$.

Figure 9 shows the contribution of end thrust effects for two different end cap thicknesses, again for fundamental and fifth overtone $6 \mathrm{MHz}$ plates. At the right top of Fig. 9 we see that the end thrust effect is small until $\ell / h$ is less than 6 . This is the isolation effect offered by the longer cylinders. Also note on the right in Fig. 9 that for the longer cylinders (shell theory) that there is a marked reduction in the effect for the thicker plate. On the left we see that short $l$ configurations (plate theory) can have a sizable end thrust effect for the thinner resonators. Combination of the results in Figs. 8 and 9 gives the expected transfer function with all effects included. Figure 10 does this and also includes measured data points from three actual transducers of the indicated dimen- 
sions. The overall agreement is excellent considering the gross approxillitions, particularly in the plate theory.

Detailed numerical calculations were carried out for the three experimental geometries measured. The calculations used a finite difference code ${ }^{11}$ called BMINES. The results are indicated by the +'s in Fig. 10. The agreement is excellent between the detailed numerical calculations and the experimental results.

The general agreement seen in Fig. 10 between experiment and the two theories establishes that the simple modeling in Eq. 7 and Tables I-III contains the essential static stress effects. Further modeling for $\ell \leq h$ and $\ell \geq 4 \mathrm{~h}$ will be done with the approximate models in Tables I-III. Any geometries with $h<\ell<4 h$ will require the BMINES, or an equivalent, computer code.

Maximum Pressure Considerations

There are two readily identified effects at high pressure that could cause catastrophic failure of the present pressure gauge design; buckling of the resonator plate and fracture of the structure at the point of maximum tension. The critical radial load $N_{C R}$ for buckling of a clamped, circular resonator plate is described by 9

$$
\mathrm{N}_{\mathrm{CR}}=\frac{1.22 \mathrm{E}_{\mathrm{T}}^{3}}{\left(1-\nu^{2}\right) \mathrm{a}^{2}}
$$

If $P_{\mathrm{MAX}}$ represents the pressure at which $\mathrm{N}_{\mathrm{CR}}$ is attained, Eqs. 2 and 10 lead to

$$
P_{\text {MAX }}=\frac{1.22 E T_{R}^{2}}{F\left(1-\nu^{2}\right) Q^{2}}
$$


Equation 12 tells us that overtone plates allow higher $P_{M A X}$, both from buckling stability and from their smaller $F$ values. Choice of a fundamental or overtone mode resonator plate is a tradeoff between high $F$ values versus high $P_{\text {MAX }}$ values. For instance, for $E=1 \times 10^{12} \mathrm{dyn} / \mathrm{cm}^{2}$, the $6 \mathrm{MHz}$ fundamental mode plates used to date in our work (devices in Fig. 10) have $\mathrm{P}_{\mathrm{MAX}}$ is $1.2 \times 10^{9} / \mathrm{F}$ in $\mathrm{dyn} / \mathrm{cm}^{2}$ or $17000 / \mathrm{F}$ in psi. For a fifth overtone. plate at the same frequency, $\mathrm{P}_{\mathrm{MAX}}$ is $4.2 \times 10^{5} / \mathrm{F} \mathrm{psi}$.

The second failure mechanism, fracture, depends on the overall design, i.e., $h, a, \tau_{E}$, and $\tau_{R^{*}}$ It is possible to design the transducer to have no points in tension ${ }^{1}$, thus eliminating fracture from practical consideration. If such a design does not satisfy other requirements on buckling, sufficiently large F, or overall size constraints, then a design with tensile stress must be used and detailed static stress analysis must be used to identify the maximum tensile stress. For long $l$ geometries, this has been done. ${ }^{1}$ The result is that tensile stress will occur on the outer surface at the resonator edge. The stress $T$ there is the tensile stress from the inward bowing of the unsupported cylinder superimposed with the longitudinal compressive stress from the pressure on the end caps:

$$
T=\frac{3 P}{\beta^{2} h^{2}}\left[1-\frac{F h(1-v)}{a}\right]\left[\frac{\sinh \beta l-\sin \beta l}{\sinh \beta l+\sin \beta l}\right]-\frac{a P}{2 h}
$$

As an example, the long $\ell$ device in Fig. 10 has $T \approx 1.5 \mathrm{P}$. Since quartz typically fails around 14,000 psi, the buckling condition of $17,000 / 5.1=$ 3333 psi in Eq. 11 limits $\mathrm{P}_{\mathrm{MAX}}$ for this particular geometry.

Equation 13 is of value only for long $\ell$ designs. For other cases, 
BMINES or an equivalent analysis code must be used to locate the point of maximum tensile stress and obtain quantitative values for that tensile stress.

Chemical polishing of the surfaces expected to go into tension will greatly increase the fracture strength of quartz. 12 A quantitative value for fracture strength of this chemically polished quartz is not yet firmly established but should push the numbers significantly upwards. 


\section{FABRICATION TECHNOLOGY}

Electrode Considerations

Conventional electrode procedures for quartz resonators involve $\mathrm{Au}$ electrodes on the acoustically active regions and $\mathrm{Au}$ electrodes with a $\mathrm{Cr}$ underlayer for the bonding areas. It has been found in the hybrid circuit community that $\mathrm{Cr}$ migrates at $300^{\circ} \mathrm{C}$ and lessens adhesion. Separation of the $\mathrm{Cr} / \mathrm{Au}$ electrode from substrates (usually $\mathrm{Al}_{2} \mathrm{O}_{3}$ ceramics) and wire bond failures are common. Considerable effort has been spent here on electrode technology. Both $\mathrm{Mo} / \mathrm{Au}$ and $\mathrm{Nb} / \mathrm{Au}$ sputtered electrodes have been investigated.

The $\mathrm{Nb} / \mathrm{Au}$ electrode system maintains adhesion after repeated cycling to $300^{\circ} \mathrm{C}$ in air. However, Rutherford backscattering studies show that $\mathrm{O}_{2}$ from the air migrates through the $\mathrm{Au}$ and reacts with the underlying $\mathrm{Nb}$. Such a reaction does not affect adhesion, but is undesirable since any reacted $\mathrm{O}_{2}$ from the environment inside the transducer represents mass added to the resonator surface. If such electrodes are used near or on the acoustically active region, it will lower the resonant frequency and cause continuing downward drift in frequency of an order comparable to the frequency shifts due to pressure. The $\mathrm{Nb} / \mathrm{Au}$ system was abandoned in favor of $\mathrm{Mo} / \mathrm{Au}$.

The Mo/Au system has provided excellent adhesion to quartz in repeated temperature cycling and does not have the $\mathrm{O}_{2}$ reaction problems of $\mathrm{Nb} / \mathrm{Au}$. Typical electrodes are keyhole patterns with $500 \AA$ of Mo followed by 3000 $\AA$ of Au without breaking vacuum. The sputtering is accomplished in a twotarget dc sputtering chamber with a motorized holder which can position the samples beneath either the Mo or the Au targets. 
For the present investigation, the Mo/Au electrodes are used for both the acoustically active region and the bonding areas. It may be necessary to use $\mathrm{Au}$ electrodes without the Mo sticking layer in the acoustically active region to minimize drift in the final design. If this proves necessary, the Au can be made to adhere adequately in these regions by using ozone precleaning ${ }^{13}$ and deposition at $300^{\circ} \mathrm{C}$ substrate temperature. The electrode mask set is designed so that the tab of the keyhole pattern extends over the edge and down the side of the resonator plate. This region is coated during the sputtering and thus provides electrical communication from the outside to the acoustically active region after assembly.

Bonding Agent

The bonding agent chosen for assembly of the quartz pieces was Pyroceram 89 applied by silk screening or the equivalent VITA Tape applied as a tape on the mating surfaces. These are glass/ceramic materials with an organic binder. The binder is first burned out in air at $300^{\circ} \mathrm{C}$ for 4 hours. Three small bumps are silkscreened on either side of the resonator plate to hold the pieces apart in final assembly so that a vacuum can be pulled on the hollowed-out volumes of the end caps and subsequently backfilled with He or Ar.

It has been found that the bonding agent dissolves Mo/Au. The region where the electrode tab passes through the bond is protected by $5000 \AA$ of $\mathrm{Cr}$ deposited in a separate deposition. The $\mathrm{Cr} /$ bonding agent and $\mathrm{Cr} / \mathrm{Au}$. interfaces have been found to hold up to temperature cycling, in contrast to the adherence failure of the $\mathrm{Cr} /$ quartz interface under temperature cycling.

The three pieces, two end caps and the resoneotr plate, are assembled 
and aligned cyrstallographically by aligning small flats ground on their edges to identify the crystallographic directions. The assembly is held in alignment by a stainless steel sleeve slipped over the outside. The sleeve is slightly shorter than the final assembled height to allow pressure to be applied to the pieces during the sealing.

The piece parts in their sleeve are placed in a vacuum furnace with a weight on top of the assembly. Temperature is raised to just below the melting point of the glass bonding agent $\left(400^{\circ} \mathrm{c}\right)$ and the system is repeatedly evacuated and backfilled with He or Ar. Then the temperature is raised to above the melting point of the glass to $455^{\circ} \mathrm{C}$ and the seal is made by the weight applied. The temperature is then held at $455^{\circ} \mathrm{C}$ for one hour to cause crystallization of the bonding agent. The resulting bond is a ceramic with a melting point far in excess of the sealing temperature and of any expected operating temperatures. The glass/ceramic was chosen because of this ability to make the initial seal as a glass and then convert to a mechanically stable ceramic form.

The results to date on this fabrication procedure have been satisfactory. Preliminary testing has not turned up any significant problems. 


\section{PRELIMINARY PRESSURE MEASUREMENTS AT $275^{\circ} \mathrm{C}$}

Measurements of pressure at $275^{\circ} \mathrm{C}$ have been accomplished. The rotated $X$-cut $\left(\theta=35^{\circ}\right)$ transducer was suspended from two electrical feedthroughs on the inside of a pressure bomb filled with silicone oil. The assembly was either used at room temperature for the data of Fig. 10 or heated in a furnace to $275^{\circ} \mathrm{C}$. Connections were made to the crystal via the feedthroughs. Wires from the feedthroughs were connected to an oscillator circuit outside the furnace. Oscillator frequency was monitored as the bomb was pressurized with a hand pump. Independent pressure measurements were taken with a Paroscientific Model 600 Digiquartz Pressure Computer and Model $75 \mathrm{~K}$ gauge located outside the furnace and connected into the pressure line with a "T" junction. The Paroscientific gauge has been checked in our standards lab with a dead weight tester to approximately 1 psi resolution ( 5000 psi full scale).

Results are shown in Fig. 11 as fractional frequency shift vs absolute pressure. Data repeatability and hysteresis effects were approximately 4 psi at $275^{\circ} \mathrm{C}$ and 2 psi at room temperature. These relatively high values seem to be related more to time-dependent flow of the viscous oil in the tubing of the experiment and temperature changes in the pressure bomb due to cold oil being pumped in during pressure increases than to effects in the quartz resonator itself. More careful design to limit the oil volume around the transducer and to preheat the oil during pressure-up will be necessary to demonstrate the full capability of the quartz resonator gauge. 


\section{CONCLUSIONS}

This document summarizes the major aspects of our present technology for quartz resonator pressure transducers and shows preliminary pressure measurements at $275^{\circ}$ C. Refinements may be necessary as detailed characterization of the device performance continues. One identifiable area for improvement is the use of swept quartz to avoid the $Q$ drop at high temperatures. Also, the expensive machining used in the HP design is necessary to move the bonds away from the resonator plate. This was done to reduce hysteresis from yielding in the bonding agent. The extent of hysteresis effects in our device has not been evaluated yet. More detailed testing 4 of the device and down-hole logging experience will be necessary to evaluate the impact of hysteresis in logging applications.

\section{ACKNOWLEDGEMENTS}

J. B. Snelling has provided the electrode technology development and numerous helpful suggestions on overall design. G. D. Peterson performed the Rutherford backscattering analyses on the $\mathrm{O}_{2}$ gettering effect of the electrodes at high temperature. Helpful discussions and cooperative effort in some of the experiments occurred on a continuing basis with T. D. McConnell. The glass shops assistance from R. Snidow and C. Tuthill has been instrumental in this development. J. Tillerson and M. Madsen performed the BMINES calculations. 
1. H. E. Karrer and J. Leach, "A Quartz Resonator Pressure Transducer", IEEE Trans. Ind. Elec, and Control Instr. IECI-16, p. 44 (1969).

2. J. Paros, "Digital Pressure Transducers", Measurements and Data, Issue 56, Vol. 10, No. 2, March-April 1976.

3. E. P. EerNisse, "Quartz Resonator Frequency Shifts Arising from Electrode Stress", Proc. 29th Annual Frequency Control Symposium, p. 1 (1975).

4. A. Ballato, E. P. EerNisse, and T. Lukaszck, "The Force-Frequency Effect in Doubly Rotated Quartz Resonators", Proc. 31st Annual Symposium on Frequency Control, p. 8 (1977).

5. E. P. EerNisse, "Rotated X-Cut Quartz Resonators for High Temperature Applications", Proc. 32nd Annual Symposium on Frequency Control (1978).

6. "Standards on Piezoelectric Crystals", Proc. IRE 37, p. 1378 (1949).

7. M. Onoe, et al., "Quartz Crystal Accelerometer Insensitive to Temperature Variation", Proc. 3lst Annual symposium on Frequency Control, p. 62 (1977).

8. E. P. EerNisse, et al., "Variational Calculation of Force-Frequency Constants of Doubly Rotated Quartz Resonators", IEEE Trans. Sonics and UItrasonics SU-25, p. 132 (1978).

9. S. Timoshenko and S. Wornowsky-Krieger, Theory of Plates and Shells, McGraw-Hill, 1959.

10. S. Timoshenko and J. N. Goodier, Theory of Elasticity, McGraw-Hill, 1970.

11. U. S. Bureau of Mines, Final Tech. Report, Vols. 1 and 2, April 1973. U.S.B.M. Contract Number H0220035.

12. J. R. Vig, et al., "Chemically Polished Quartz", Proc., 3lst Annual Symposium on Frequency Control, p. 131 (1977).

13. J. R. Vig, et a1., "Surface Studies for Quartz Resonators", Proc. 28th Annual Symposium on Frequency Control, p. 96 (1974). 
TABLE I

Equations For End Thrust Contribution (Long \& Model)

$$
\begin{gathered}
D B M_{E}-A Q_{E}+\left[\frac{B}{2}+\frac{a \beta^{3} h^{3}}{3 \tau_{R}(1+v)}\right]=0 \\
{\left[B E-\frac{a h^{3} \beta^{3}}{\tau_{E}^{2}(1+v)}\right]_{E}-\left[C+\frac{5 a h^{3} \beta^{3}}{12 \tau_{E}(1+v)}\right] Q_{E}+A Q_{R}=-\frac{a^{3} h^{3} \beta^{3} P}{8 \tau_{E}^{2}(1+v)}} \\
{\left[\beta F+\frac{2 a h^{3} \beta}{\tau_{E}^{2}(1+v)}\right]_{E}-\left[E-\frac{a h^{3} \beta^{2}}{\tau_{E}^{2}(1+v)}\right]_{E}+D Q_{R}=\frac{a^{3} h^{3} \beta^{2} P}{4 \tau_{E}^{3}(1+v)}}
\end{gathered}
$$




\section{TABLE II}

Equations For Parameters in Table I

$$
\begin{aligned}
\alpha & \equiv B l \\
\mathrm{DEN} & \equiv \sin \alpha \cos \alpha+\sinh \alpha \cosh \alpha \\
\mathrm{A} & \equiv \cos \alpha \cosh \alpha / \mathrm{DEN} \\
\mathrm{B} & \equiv\left(\cos ^{2} \alpha+\cosh ^{2} \alpha\right) / \mathrm{DEN} \\
\mathrm{C} & \equiv\left(\sin ^{2} \alpha+\cosh ^{2} \alpha\right) / \mathrm{DEN} \\
\mathrm{D} & \equiv(\cos \alpha \sinh \alpha-\sin \alpha \cosh \alpha) / \mathrm{DEN} \\
\mathrm{E} & \equiv\left(\sinh ^{2} \cosh \alpha-\sin \alpha \cos \alpha\right) / \mathrm{DEN} \\
\mathrm{F} & \equiv\left(\cosh ^{2} \alpha-\cos ^{2} \alpha\right) / D E N
\end{aligned}
$$




\section{TABLE III}

Equations For Transfer Function (Short $\ell$ Model)

Neglecting End Thrust

$$
\begin{aligned}
& \frac{a}{l h} Q_{E}+\left[\frac{a}{l h}+\frac{2(I-v)}{\tau_{R}}\right] Q_{R}=P\left[\frac{a}{h}-1+v\right] \\
& {\left[\frac{a}{h l}+\frac{(I-v)}{\tau_{E}}\right] Q_{E}+\frac{a}{h l} Q_{R}=P\left[\frac{a}{h}-1+\nu\right]}
\end{aligned}
$$

End Thrust Contribution

$$
\begin{aligned}
& \frac{a}{\ell h} Q_{E}^{-}+\left[\frac{a}{\ell h}+\frac{2(1-v)}{\tau_{R}}\right] Q_{R}^{-}=0 \\
& {\left[\frac{a}{h l}+\frac{4(I-v)}{\tau_{E}}\right] Q_{E}+\frac{a}{h l} Q_{R}^{-}=\frac{3 a^{2}(I-v) P}{4} \tau_{E}^{2}}
\end{aligned}
$$




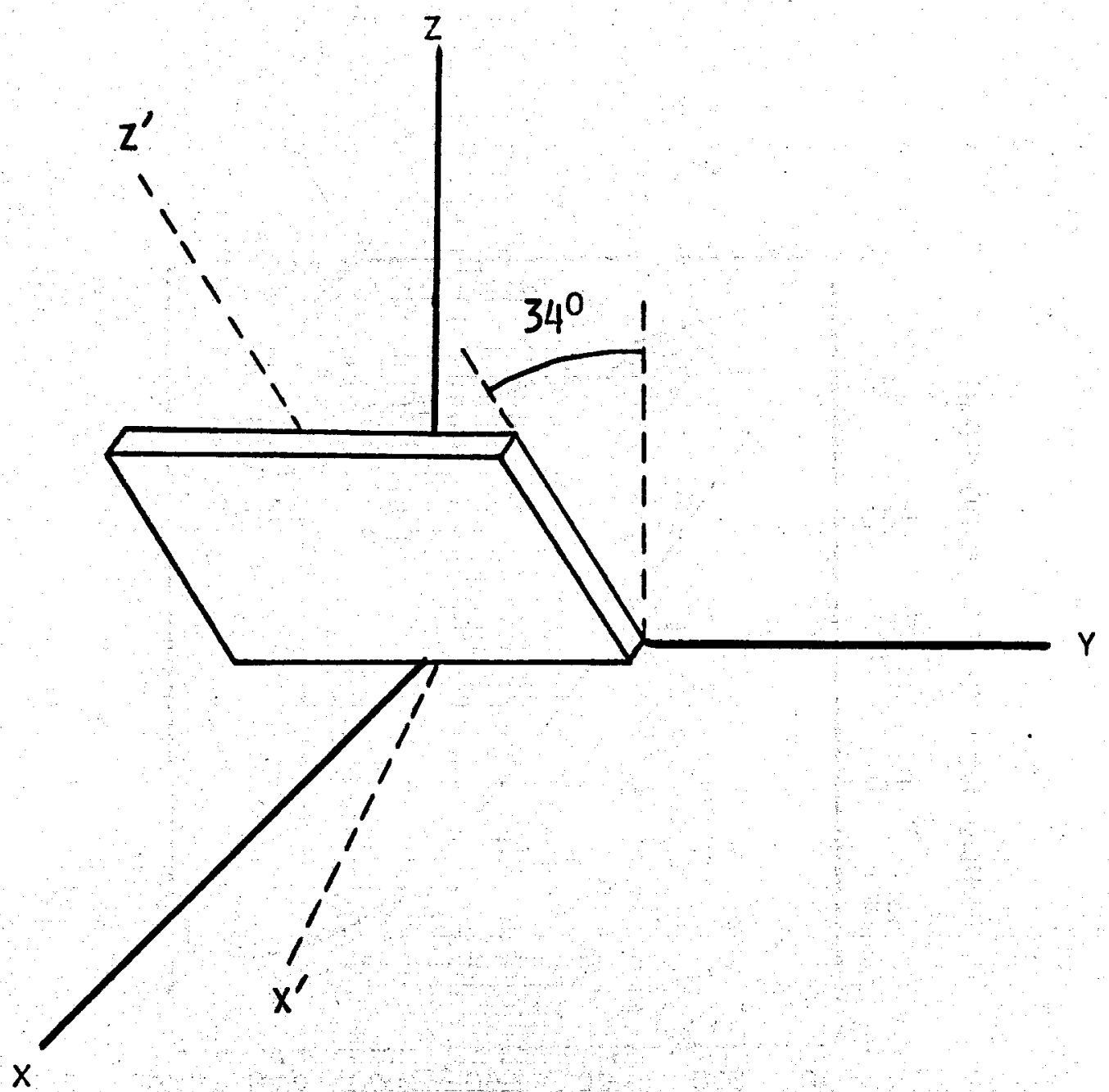

ROTATED X-CIJT NUARTZ.

$(x y l) 34^{\circ}$
OR $(Y x w \ell) 30^{\circ}, 34^{\circ}$

Figure 1. Crystallographic orientation called the Rotated X-cut, (xyl) $34^{\circ}$ or (yxwl) $30^{\circ}, 34^{\circ}$. 


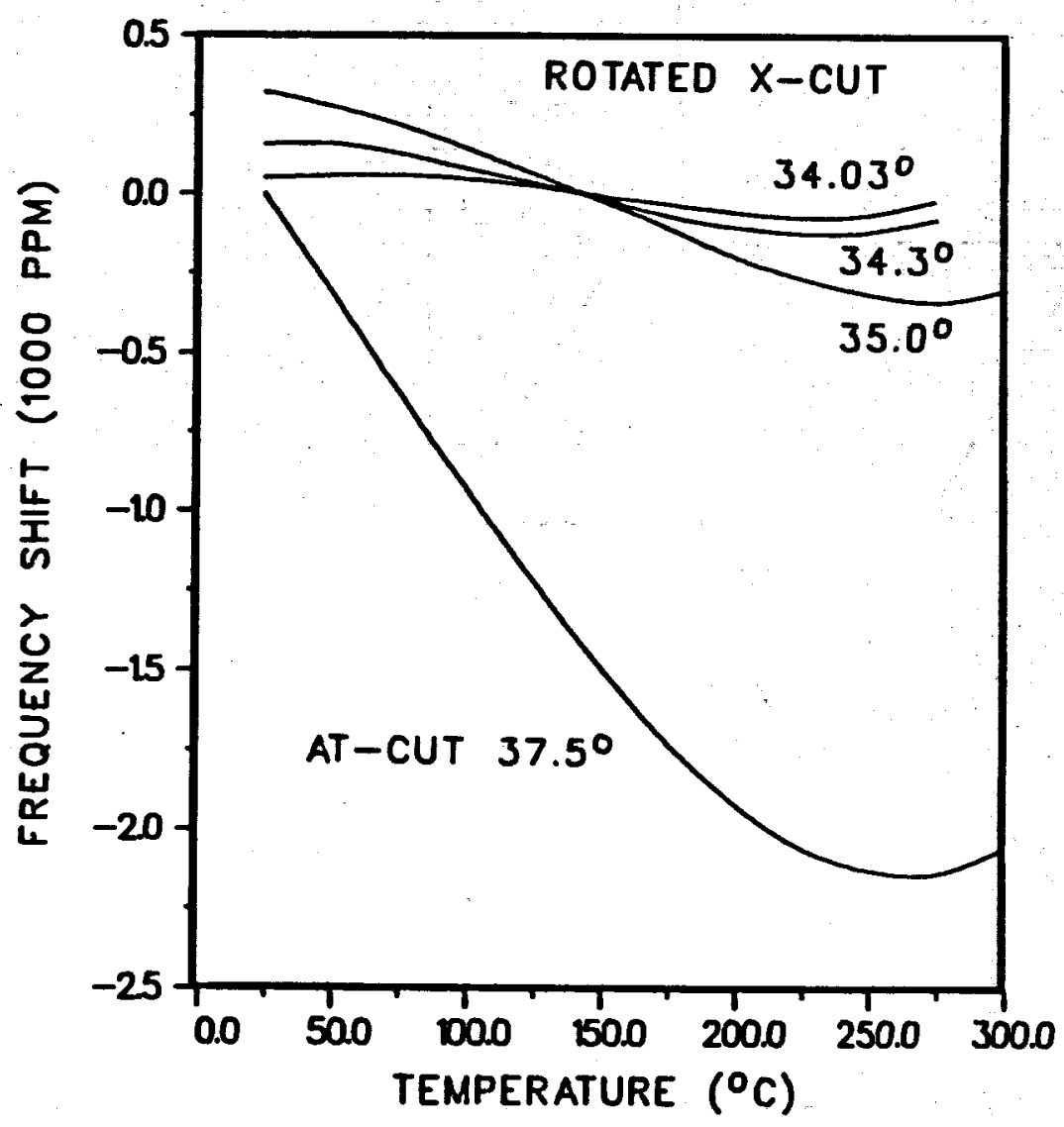

Figure 2. Measured frequency versus temperature characteristics for the Rotated X-cut. The typical AT-cut chosen for a $275^{\circ} \mathrm{C}$ turning point is included for comparison. 


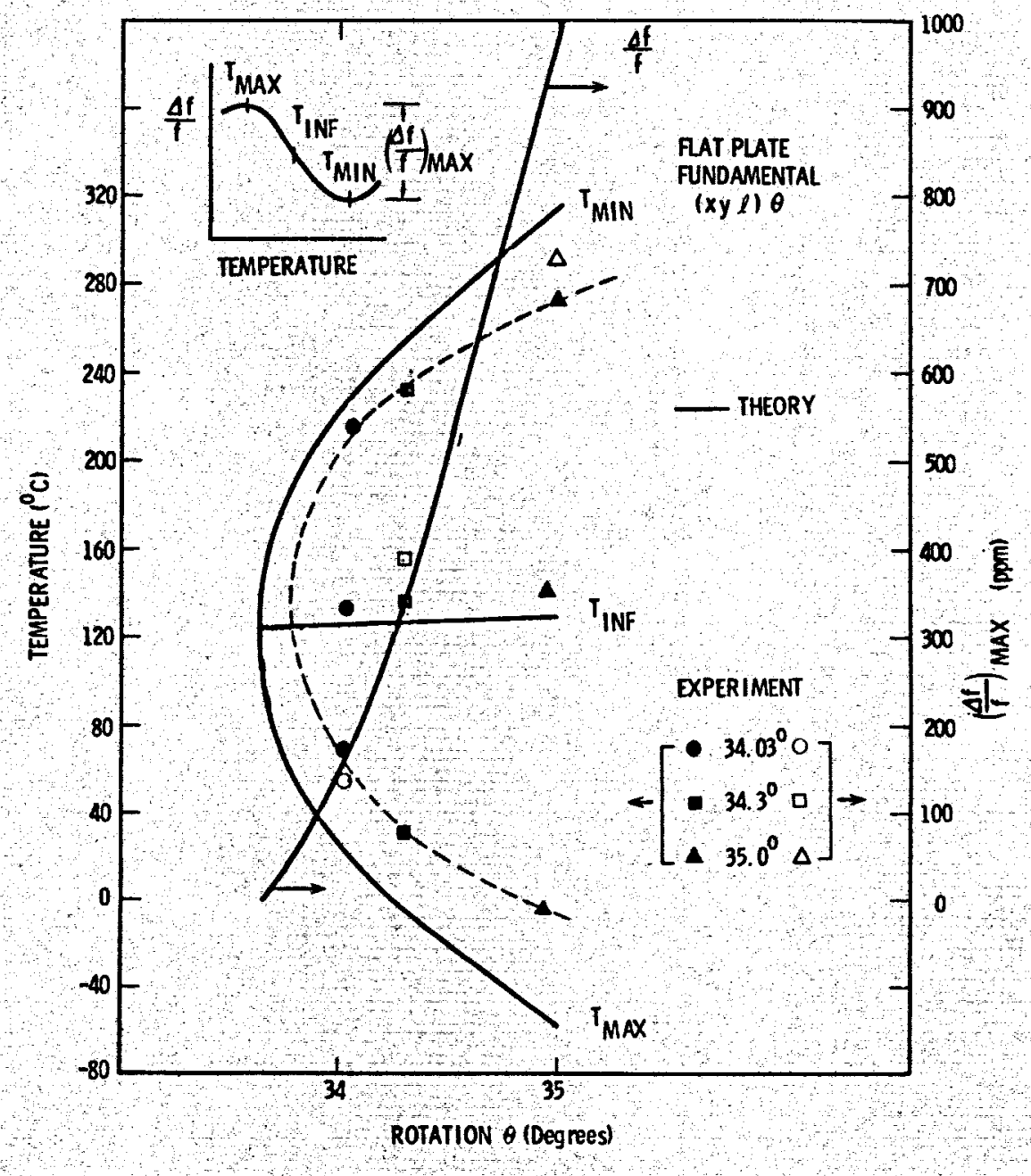

Figure 3. Turning point temperatures and maximum frequency deviation, both experiment and theory, versus $\theta$ for the Rotated $\mathrm{X}$-cut. 


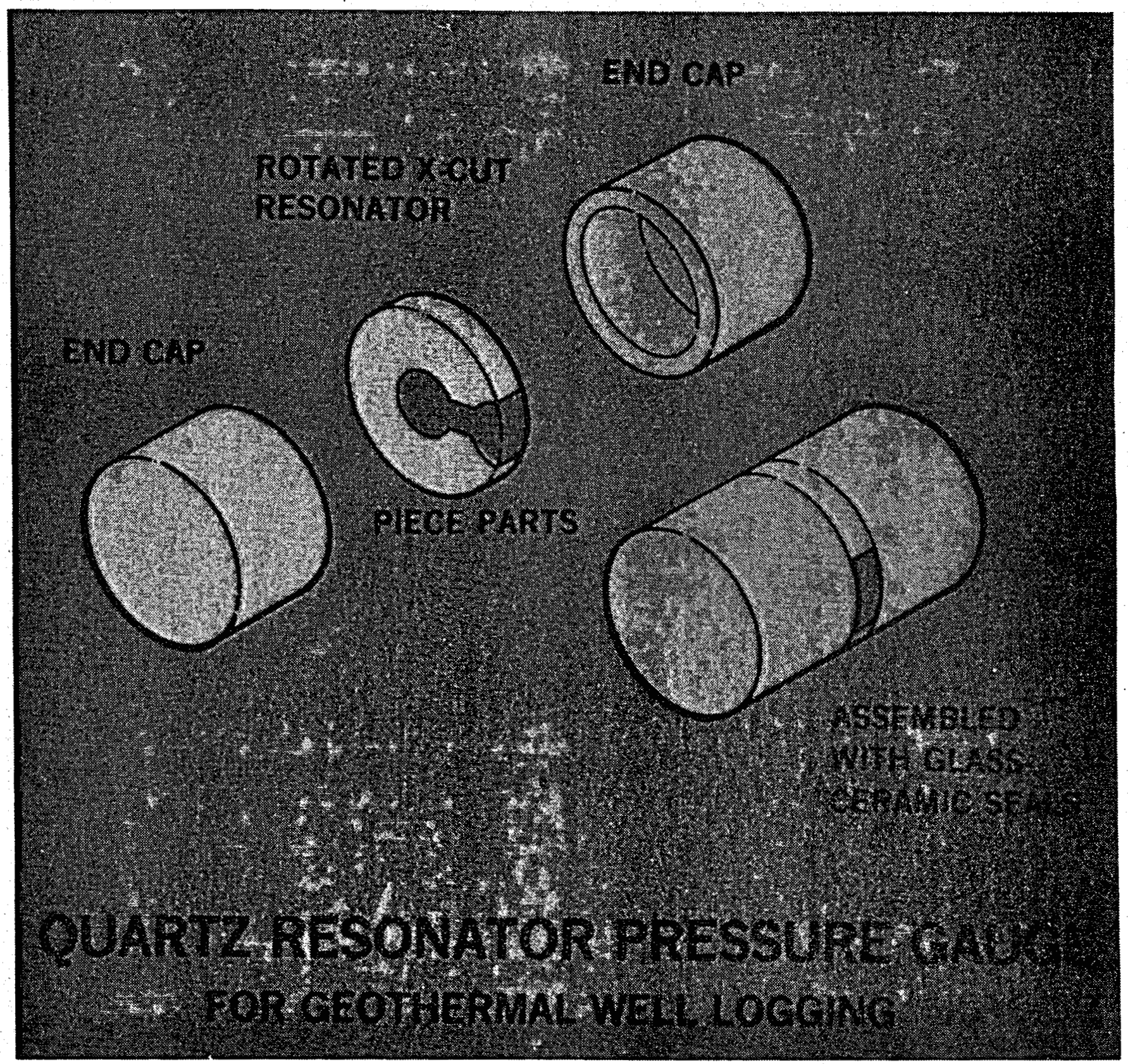

Figure 4. Sketch of the Pressure Gauge. 


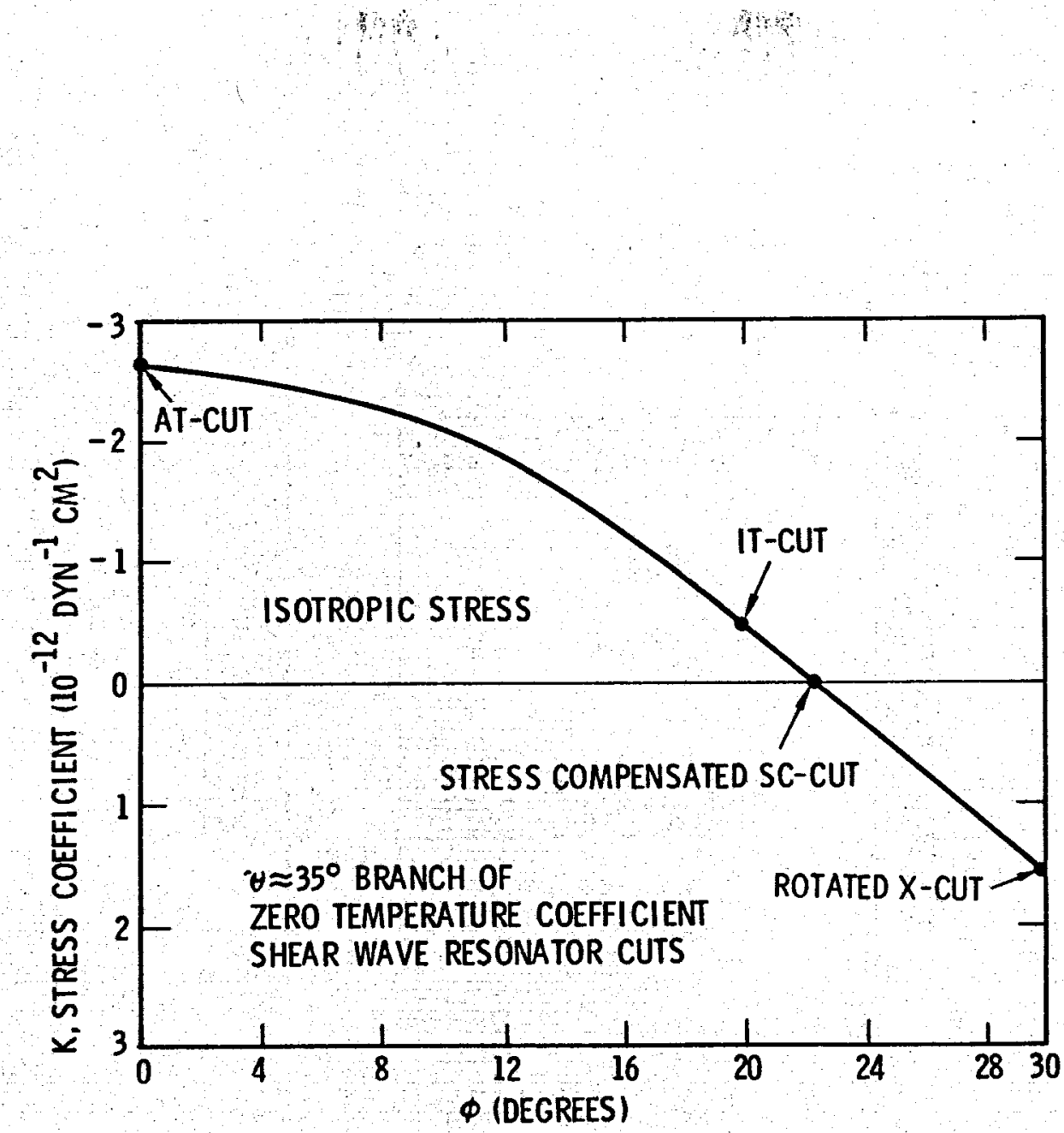

Figure 5. Stress coefficient for the important (yxwl) $\$, 34^{\circ}$ branch which contains the widely used AT-, IT-, SC-, and the Rotated X-cuts. 


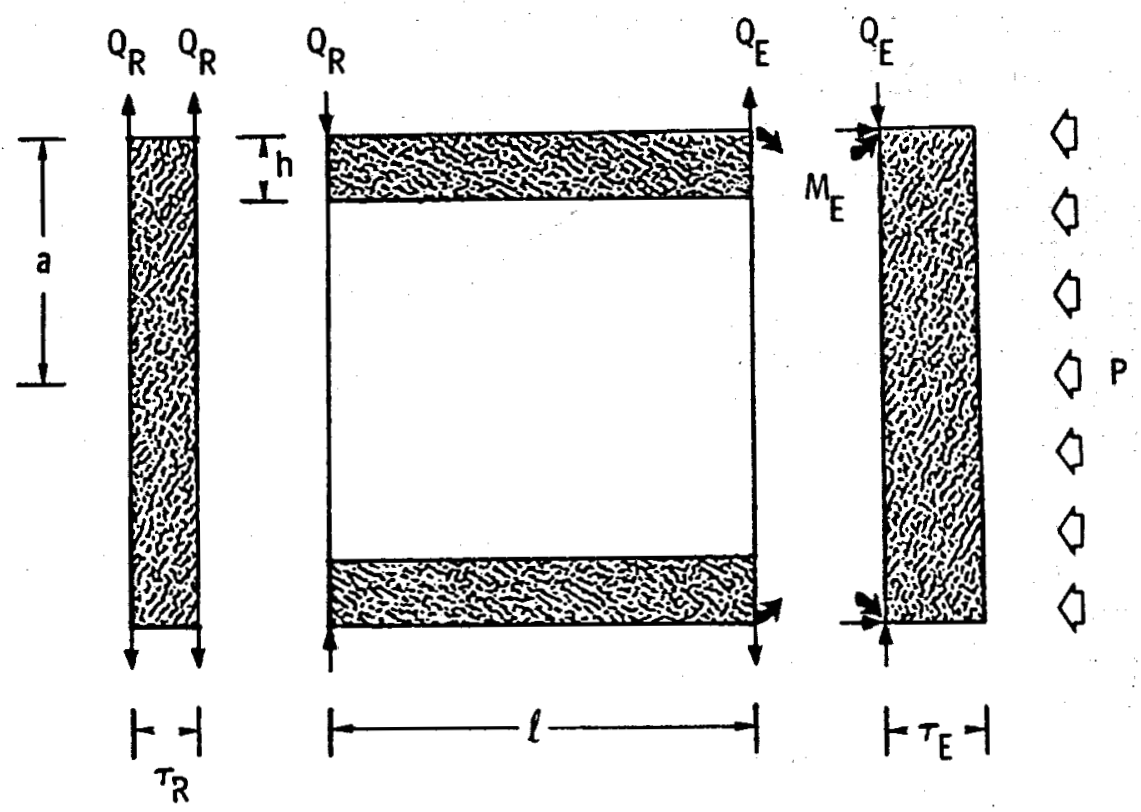

Figure 6. Cross-section of the resonator and right hand side of the pressure gauge showing the forces and moments acting on the various sections when $\ell>h$. 

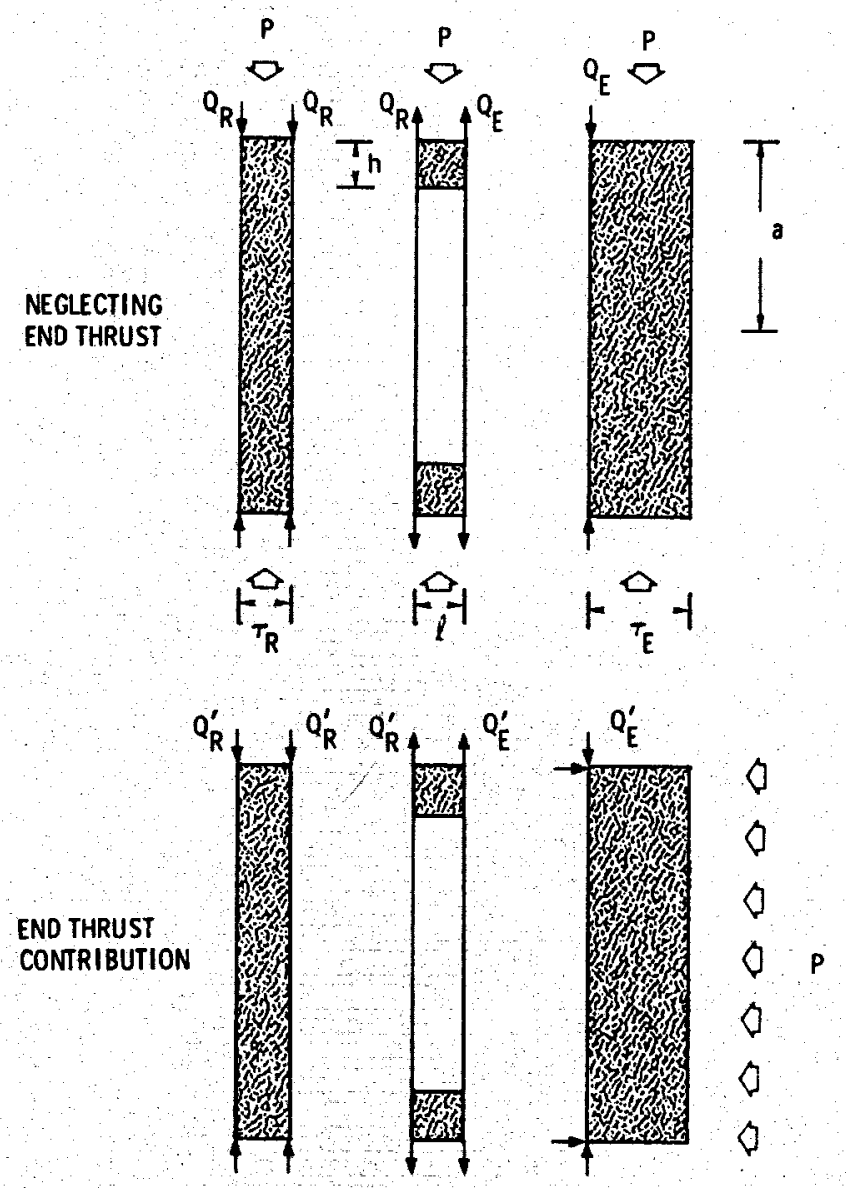

Figure 7. Cross-section of the resonator and right hand side of the pressure gauge showing the forces acting on the various sections when $\ell<h$. Upper portion shows effects when end thrust is neglected. Lower portion shows end thrust effects. 


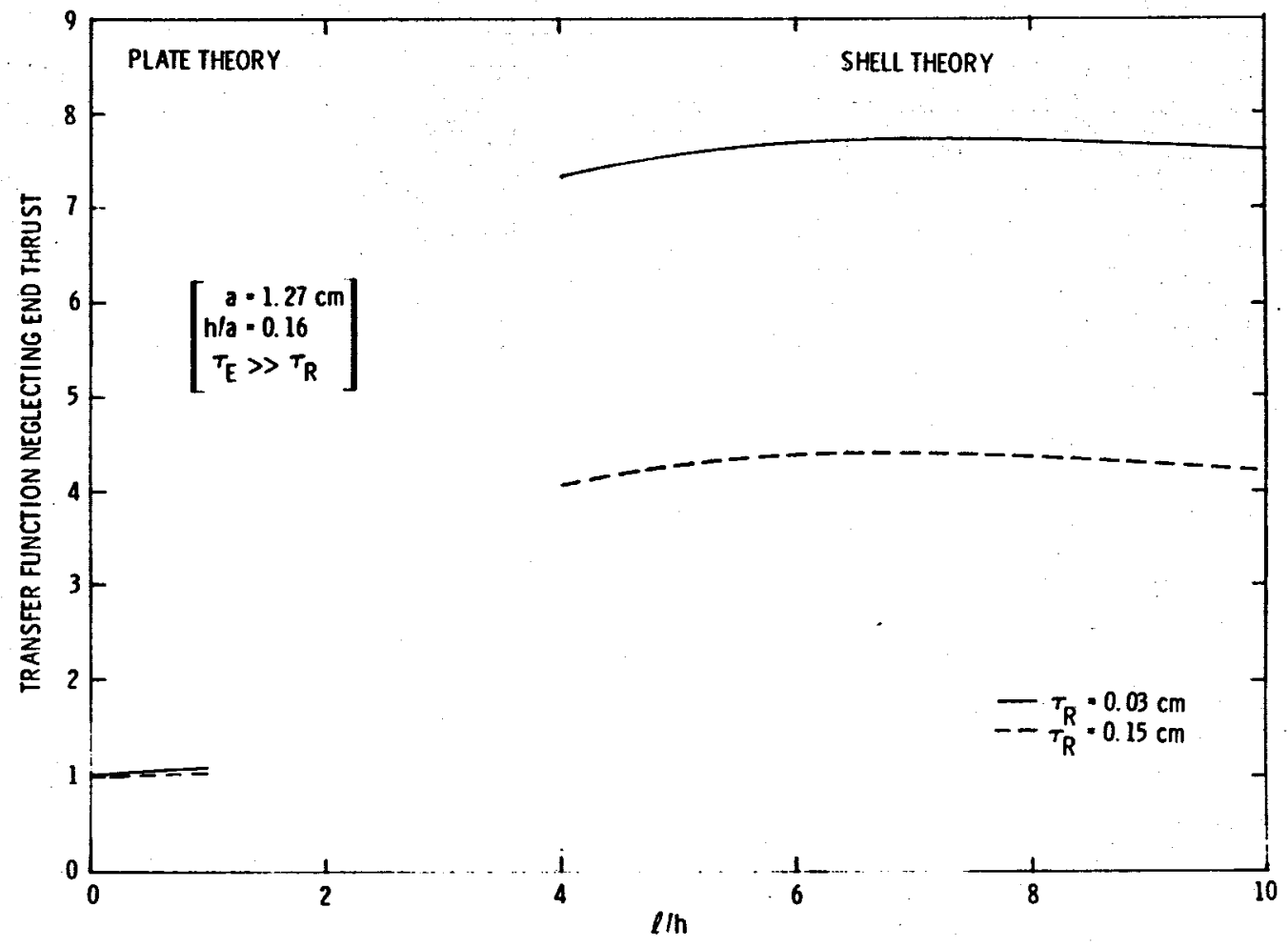

Figure 8. Transfer function for the pressure gauge of Fig. 4 as a function of $\ell / h$ if end thrust effects are ignored. A fundamental $6 \mathrm{MHz}(0.03 \mathrm{~cm})$ and $6 \mathrm{MHz}$ fifth overtone $(0.15 \mathrm{~cm})$ are shown. Theoretical formulas are in Tables I-III. 


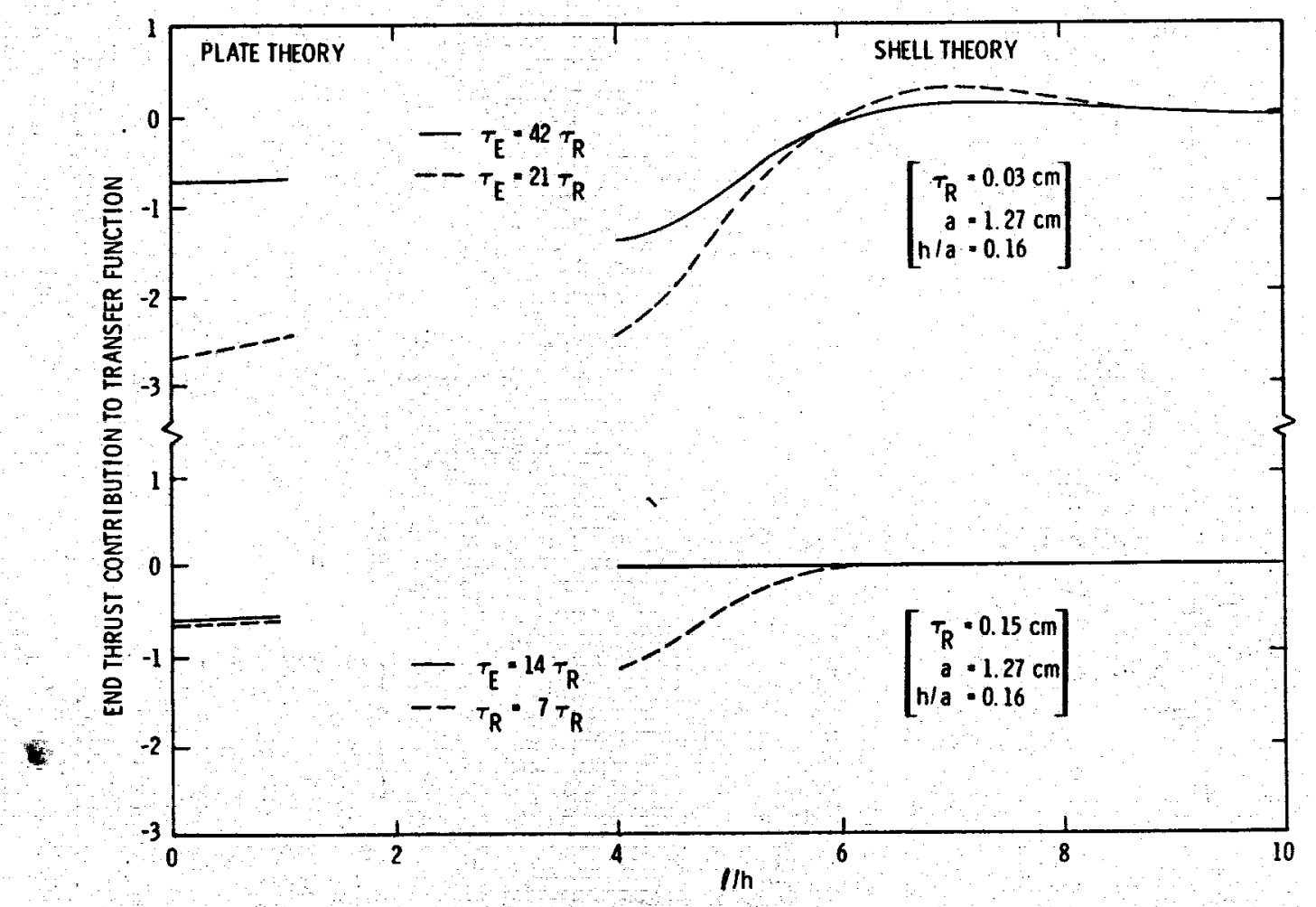

Figure 9. Contribution to the transfer function from end thrust (bowing of end caps) versus $l / h$ ratio for devices in Fig. 8. Theoretical formulas are in Tables I-III. 


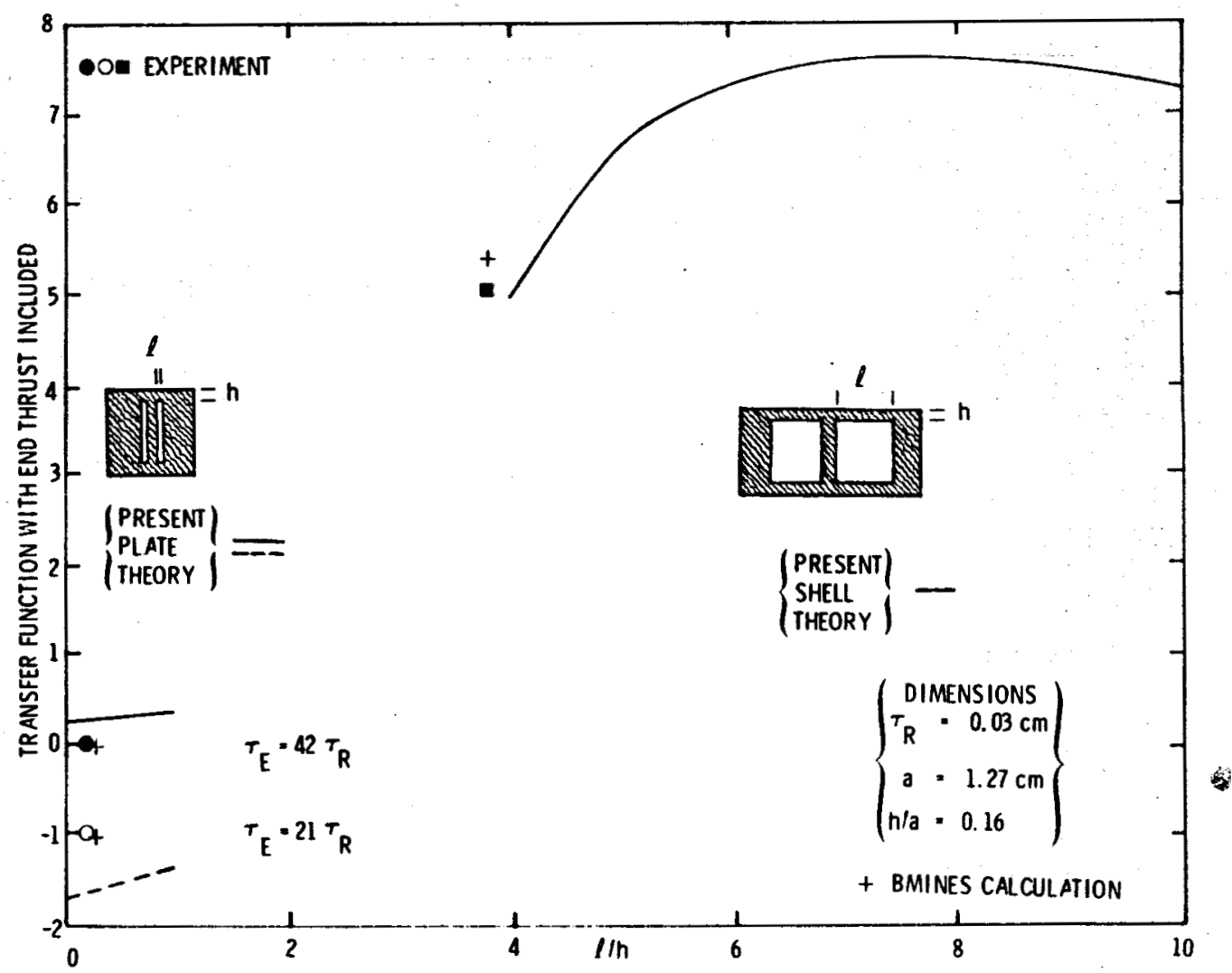

Figure 10. Transfer function of the pressure gauge in Fig. 4 versus $l / h$ ratio when all effects are combined. Experimental results are included to verify the validity of the modeling described in Tables I-III. BMINES data are finite difference calculations. 


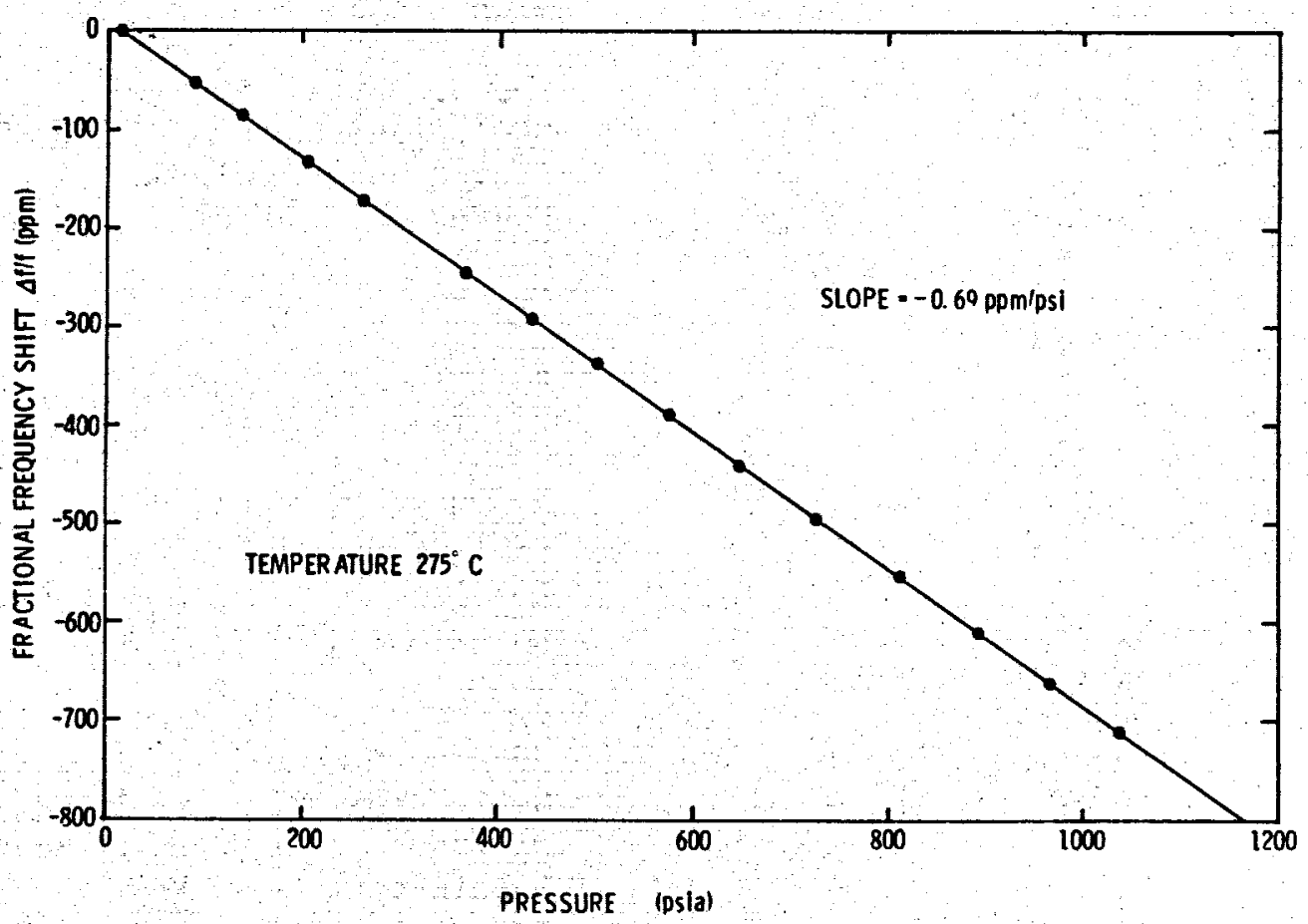

Figure 11. Fractional frequency shift vs pressure measured at $275^{\circ} \mathrm{C}$ for a rotated $\mathrm{X}$-cut quartz resonator pressure gauge. 
UNLIMITED RELEASE

\section{INITIAL DISTRIBUTION}

Mr. Ron Anderson

Schlumberger Well Services

5000 Gulf Freeway

Houston, TX 77023

Mr. Ed Basham

G-0 Wireline Services

P. 0. Box 1258

Fort Worth, TX 76101

Mr. Bruce Blackman

Halliburton Services

P. 0. Box 1431

Duncan, OK 73533

Dr. William Brigham, Jr.

Stanford University

Petroleum Engineering Dept.

Stanford, CA 94305

Mr. Donald A. Campbell

Sr. Staff Reservoir Engineer

Republic Geothermal, Inc.

11823 E. Slauson Ave., Suite 1

Santa Fe Springs, CA 90670

Mr. Bert Dennis

Los Alamos Scientific Laboratory

Mail Stop 980

Los Alamos, NM 87544

Mr. Lyman M. Edwards

Technical Consultant

Dresser Industries, Inc.

P. 0. Box 6504

Houston, TX 77005

Mr. James C. Harper

Geophysical Research Corp.

136 Mohawk BIvd.

Tulsa, OK 74106

Dr. John H. Howard

Registered Geologist

Lawrence Berkeley Laboratory

One Cyclotron Road

Building 90, Room 2071

Berkeley, CA 94720
Dr. H. E. Karrer

Hewlett-Packard Laboratories

1501 Page Mill Road

Palo Alto, CA 94304

Dr. W. E. Kenyon

Dr. J. Brown

Schlumberger-Doll Research Center

P. 0. Box 307

Ridgefield, CT 06877

Mr. W. Scott Keys

Geological Survey, Bldg. 25

Denver Federal Center

Denver, co 80225

Mr. Bob L. Lawson

71-C

Phillips Petroleum Co.

Bartlesville; OK 74114

Mr. Mark Matthews

Mail Stop 573

Los Alamos Scientific Laboratory

Los Alamos, NM 87544

Mr. Clifton McFarland

Program Manager

U. S. Department of Energy

Division of Geothermal Energy

Washington, DC 20545

Mr. Jerome Paros

President

Paroscientific, Inc. 4500 148th Avenue, NE

Redmond, WA 98052

Mr. Robert C. Ransom

Union Oil Research Center

P. 0. Box 76

Brea, CA 92621

Mr. Werner J. Schwarz

Program Manager

Lawrence Berkeley Laboratory

Building 90, Room 1012-A

University of California

Berkeley, CA 94720 


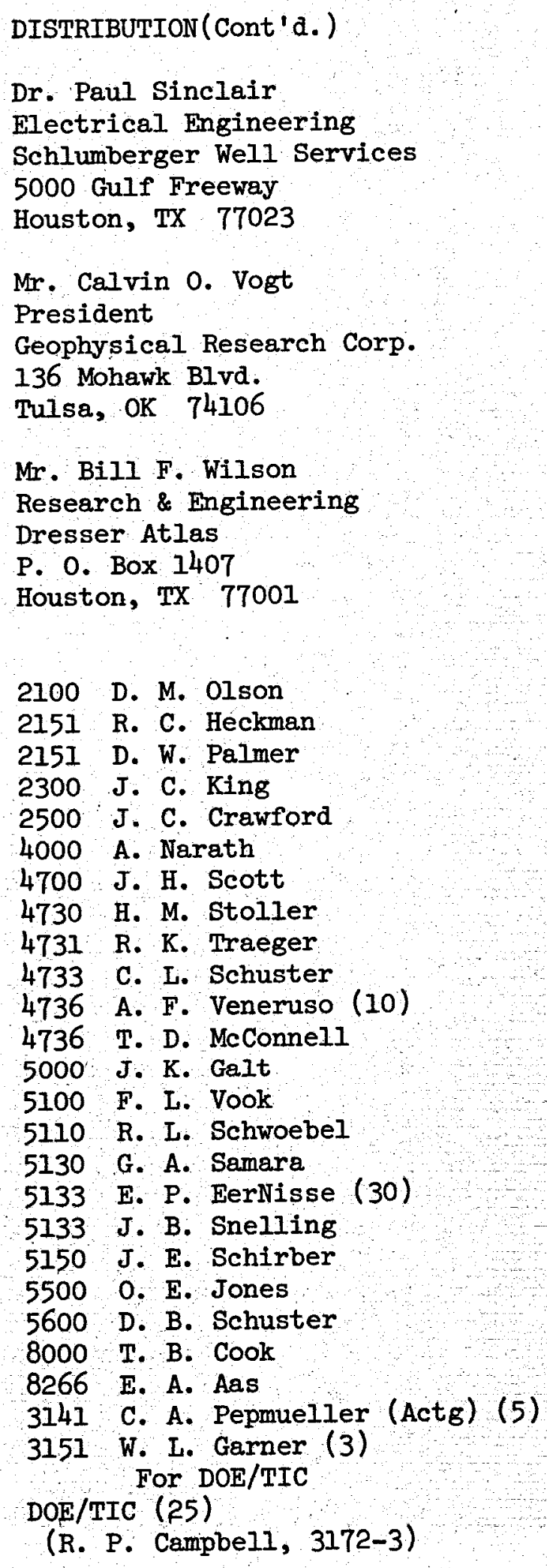

